\title{
Impact of footwear fitting on foot shape in primary schoolgirls
}

\author{
Ewa PusZCZAŁOWSKA-LizIS ${ }^{1 *}$, PAULINA ZARZYCZNA ${ }^{2}$, WIOLETTA MIKULÁKOVÁ $^{3}$ \\ ${ }^{1}$ Medical College, Institute of Health Sciences, University of Rzeszów, Rzeszów, Poland. \\ ${ }^{2}$ Non-Public Health Care Institution, Center of Physical Rehabilitation „Tutmed”, Sanok, Poland. \\ ${ }^{3}$ University of Presov, Faculty of Health Care, Department of Physiotherapy, Slovakia.
}

\begin{abstract}
Purpose: The study aimed to analyze the footwear fitting and its impact on foot construction features in primary schoolgirls. Methods: The study group was comprised of 100 girls aged 9 years. The study relied on the CQ-ST podoscope and the Clevermess device for pertinent measurements. The data were analyzed based on the Mann-Whitney $U$-test, multiple regression analysis and simple regression. Results: Too short right footwear had $37 \%$ of the girls and the left $-38 \%$ of the girls, while too long shoes were worn respectively by: $14 \%$ of the girls and $15 \%$ of the girls. Too wide footwear in relation to the right foot width had $45 \%$ of the group and in relation to the left foot: $41 \%$ of the group. Too narrow right shoes had $23 \%$ of the group and the left $-32 \%$ of the group. Statistically significant influence of the excess of outdoor footwear width was found on the Clarke's angle values $(p=0.041)$, the fifth toe setting of the right foot $(p=0.015)$ and Wejsflog index of the left foot $(p=0.036)$. Conclusions: Most 9-year-old girls wear poorly fitted outdoor footwear. Appropriately selected footwear in terms of the width facilitates the formation of foot architecture, but wearing too wide footwear increases the risk of hollow feet and the varus deformity of the fifth toe.
\end{abstract}

Key words: outdoor shoes, length excess, width excess, foot deformities

\section{Introduction}

From a biomechanical point of view, the foot is one of the least understood structures of the human body. It is a very complex part of motor organ, with 26 bones and numerous ligaments, tendons, intrinsic and extrinsic muscles, and is, therefore, a challenging study subject [3], [14], [15], [21]. The foot, as a supporting and carrying organ, carries the body weight and is responsible for propulsion. Due to its complex function, it is characterized by high durability. Despite its relatively small size, it is adapted to accept large static and dynamic loads. Correctly arched foot is characterized by flexibility, which enables shape adjustment to the unevenness of the ground and absorbs shocks during locomotion. The human foot is shaped throughout all life in a way that is individual for every human being [2], [7], [8], [10], [17], [20], [24]. Echarri and Forriol [6], on the basis of the analysis of the longitudinal arch of the feet in 906 girls and 945 boys from Congo, aged 3 to 12 years, emphasized that the morphology and functional development of the foot are influenced by internal factors (sex, genetics, and age) and external factors (footwear habits, loading, and physical activity).

In childhood, wearing appropriate footwear is an important issue. Functional demands from footwear should protect the feet, decrease friction between foot and floor, and provide foot stability and shock attenuation. However, footwear, which was actually invented to protect human feet from harmful effects of environment, today is seen as an indispensable product of fashion. Vital components of footwear, necessary for health, are usually ignored for the sake of fashion trends [20], [24].

\footnotetext{
* Corresponding author: Ewa Puszczałowska-Lizis, Medical College, Institute of Health Sciences, University of Rzeszów, ul. Warzywna 1A, 35-959 Rzeszów, Poland. Phone: +48 178722928, e-mail: ewalizis@poczta.onet.pl

Received: July 22nd, 2019

Accepted for publication: February 7th, 2020
} 
Dinato et al. [5] pointed out to the need to consider inter-gender differences in the foot structure in primary school children when choosing footwear. According to Delgado-Abellán et al. [4], the greatest differences between girls and boys of the same age were ball width, ball girth and instep height. The girls' feet are more often deformed due to more delicate structure.

This knowledge indicates the need for careful monitoring of the feet condition, especially in the aspect of footwear fitting. The analysis of extensive literature shows that the footwear fitting in relation to the developing foot is the issue with a limited range of empirical studies. This was the reason for undertaking the subject of the paper, the aim of which was to analyze the fitting of footwear that the 9-year-old schoolgirls wore to school (outdoor footwear) and its impact on their foot construction features. The following research questions were meant to be addressed:

1. What percentage of the surveyed girls wears shoes that are properly fitted for length and width?

2. Does the size of the functional length and width excess affect the foot construction characteristics in the girls in question?

\section{Materials and methods}

The study was performed in April 2018 on a group of 9-year-old girls attending the randomly selected schools in the Sanok administrative district. The sample size representative for the site was estimated in due consideration of $95 \%$ confidence level, and a $5 \%$ level of admissible error of fraction estimation. This number totalled 134 girls. Preliminary allocation of girls to the so estimated study group was made with the aid of simple dependent drawing method. The selected group was subsequently verified in terms of its compliance with pertinent inclusion and exclusion criteria. The inclusion criteria were: age of 9 years; lack of any diseases and/or injuries of the musculoskeletal system, lower limbs with no previous surgical interventions, including feet; no genetically-dependent hallux valgus, as confirmed through an interview. The exclusion criteria: not understanding the instructions that were necessary for the measurement procedures, refusal to participate in the trial.

Following completion of the allocation procedure, it was established that 34 girls could not take part in the study protocol because they did not meet the inclusion criteria. 100 girls were enrolled into the study.
The mean body mass of the examined girls was $\bar{x}=30.42 \pm 6.80 \mathrm{~kg}$, the mean body height was $\bar{x}=$ $132.88 \pm 6.32 \mathrm{~cm}$, while the average BMI amounted to $\bar{x}=17.09 \pm 2.82$.

The research tool was the podoscope CQ-ST (manufactured by Electronic System). The study entailed measuring of the plantar feet surfaces in a relaxed stance, with the upper limbs hanging along the body. Each time, both feet were subjected to examination. The width and foot angle were natural, unforced. The calculations included the following indices: foot length, foot width, Clarke's angle, the Wejsflog index, heel angle $\gamma$ (transverse foot arch), hallux valgus angle $(\alpha)$, the angle of the varus deformity of the fifth toe $(\beta)$.

The footwear that the children wore to school (outdoor footwear) were examined. The typical outdoor shoes for schoolgirls in Poland are laced leather sneakers or leather-like materials, on a flat plastic sole. Parents were not informed ahead on which days the data would be collected.

The footwear fitting to the feet of the examined children was tested using the Clevermess device, manufactured by Clevermess GmbH (Fig. 1).

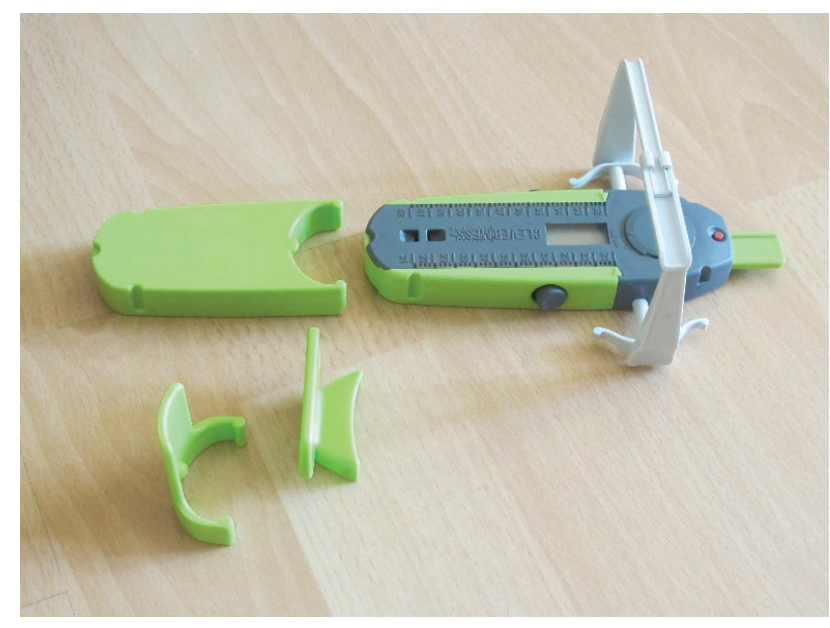

Fig. 1. Clevermess device

When assessing footwear fitting in terms of length, the following criteria were adopted:

- too short footwear - when the length excess was less than $8 \mathrm{~mm}$,

- appropriate footwear - when the length excess was $8-12 \mathrm{~mm}$,

- too long footwear - when the length excess was over $12 \mathrm{~mm}$ [19].

The following criteria were taken into account when assessing footwear fitting in terms of width:

- too narrow footwear - when the width excess was less than $1 \mathrm{~mm}$, 
- appropriate footwear - when the width excess was 1-3 mm,

- too wide footwear - when the width excess was over $3 \mathrm{~mm}$ [12], [19].

In order to preserve the integrity of the research process, all the measurements were taken in the gym, in the morning, using the same measuring instruments operated by the authors. Girls were wearing their gymnastic uniforms. For the podoscopic examination, the girls were without shoes and socks, while for measuring the footwear fitting with Clevermess device, they put on socks. Procedures were carried out in accordance with Declaration of Helsinki for experiments involving humans. All participants, their parents or legal guardians received detailed information concerning the aim and methodology used in the study. The study was approved by the Local Ethics Committee of the Rzeszów University.

Based on the gathered data, descriptive statistics were calculated. The consistency of the values with the normal distribution was verified by means of the Shapiro-Wilk test. The results for the excess of tested footwear were compared using Mann-Whitney $U$-test.
The influence of independent variables (predictive, explained such as length and width excess of footwear) on dependent variables (featured, such as foot construction) was estimated on the basis of multiple regression analysis and simple regression. The results were considered statistically significant, if the probability level of the test was lower than the predetermined significance level $p<0.05$. The Stat Soft STATISTICA application (version 13.1) was used to process the test results.

\section{Results}

Table 1 includes descriptive statistics of the foot construction characteristics in the examined girls.

The mean length excess of tested footwear was $8.99 \pm 3.51 \mathrm{~mm}$ (right shoe) and $8.91 \pm 3.66 \mathrm{~mm}$ (left shoe), while the mean width excess was $3.55 \pm 4.71 \mathrm{~mm}$ (right shoe) and $3.01 \pm 5.98 \mathrm{~mm}$ : left shoe. There were no statistically significant differences in terms of

Table 1. Descriptive statistics of structural features of the feet in the study subjects

\begin{tabular}{|l|c|c|c|c|c|c|}
\hline \multicolumn{2}{|c|}{ Feature } & $\bar{x} \pm \mathrm{SD}$ & max-min & $\mathrm{Q}_{25}$ & $\mathrm{Me}$ & $\mathrm{Q}_{75}$ \\
\hline \multirow{2}{*}{ Foot length $[\mathrm{cm}]$} & rf & $19.54 \pm 1.16$ & $22.10-17.20$ & 18.70 & 19.45 & 20.40 \\
\cline { 2 - 7 } & lf & $19.54 \pm 1.17$ & $22.10-17.20$ & 18.70 & 19.50 & 20.40 \\
\hline \multirow{2}{*}{ Foot width $[\mathrm{cm}]$} & rf & $7.43 \pm 0.47$ & $8.90-6.50$ & 7.05 & 7.40 & 7.70 \\
\cline { 2 - 7 } & lf & $7.48 \pm 0.45$ & $8.50-6.50$ & 7.15 & 7.50 & 7.70 \\
\hline \multirow{2}{*}{${\text { Clarke's angle }\left[{ }^{\circ}\right]}^{*}$ Wejsflog index } & rf & $33.38 \pm 9.49$ & $50.00-11.00$ & 29.50 & 35.00 & 40.00 \\
\cline { 2 - 7 } & lf & $32.02 \pm 10.21$ & $49.00-8.00$ & 24.00 & 34.00 & 40.00 \\
\hline \multirow{2}{*}{ Heel angle $\gamma\left[{ }^{\circ}\right]$} & rf & $2.63 \pm 0.14$ & $3.00-2.33$ & 2.54 & 2.63 & 2.72 \\
\cline { 2 - 7 } & If & $2.62 \pm 0.14$ & $2.89-2.24$ & 2.52 & 2.61 & 2.72 \\
\hline \multirow{2}{*}{ Hallux valgus angle $\alpha\left[^{\circ}\right]$} & rf & $17.30 \pm 2.00$ & $23.00-13.00$ & 16.00 & 17.00 & 18.00 \\
\cline { 2 - 7 } & If & $17.26 \pm 1.74$ & $21.00-13.00$ & 16.00 & 17.00 & 18.00 \\
\hline \multirow{2}{*}{ The angle of the varus deformity of the fifth toe $\beta\left[^{\circ}\right]$} & rf & $13.69 \pm 5.20$ & $26.00-0.00$ & 10.00 & 14.00 & 17.00 \\
\cline { 2 - 7 } & If & $13.31 \pm 5.77$ & $27.00-0.00$ & 10.00 & 14.00 & 17.00 \\
\hline
\end{tabular}

Abbreviations: rf - right foot, lf - left foot, $\bar{x}$ - arithmetical mean value, SD - standard deviation, max - maximum value, min - minimum value, $\mathrm{Q}_{25}$ - lower quartile, $\mathrm{Me}$ - median, $\mathrm{Q}_{75}$ - upper quartile.

Table 2. Descriptive statistics of the excess of tested footwear in the examined girls

\begin{tabular}{|c|c|c|c|c|c|c|c|c|}
\hline \multicolumn{2}{|c|}{ Excess of footwear [mm] } & $\bar{x} \pm \mathrm{SD}$ & $\max -\min$ & $\mathrm{Q}_{25}$ & $\mathrm{Me}$ & $\mathrm{Q}_{75}$ & $Z$ & $p$ \\
\hline \multirow{2}{*}{ Length } & rs & $8.99 \pm 3.51$ & $18.00-4.00$ & 6.00 & 8.00 & 12.00 & \multirow{2}{*}{0.20} & \multirow{2}{*}{0.837} \\
\hline & ls & $8.91 \pm 3.66$ & $18.00-2.00$ & 6.00 & 8.00 & 12.00 & & \\
\hline \multirow{2}{*}{ Width } & rs & $3.55 \pm 4.71$ & $17.00-(-6.00)$ & 1.00 & 3.00 & 7.00 & \multirow{2}{*}{1.04} & \multirow{2}{*}{0.297} \\
\hline & 1s & $3.01 \pm 5.98$ & $19.00-(-9.00)$ & -1.00 & 2.00 & 6.50 & & \\
\hline
\end{tabular}

Abbreviations: rs - right shoe, ls - left shoe, $\bar{x}$ - arithmetical mean value, $\mathrm{SD}$ - standard deviation, max - maximum value, min - minimum value, $\mathrm{Q}_{25}$ - lower quartile, $\mathrm{Me}$ - median, $\mathrm{Q}_{75}$ - upper quartile, $Z$ - value of the Mann-Whitney $U$-test statistic, $p$ - probability value. 
the excess value of length and width recorded for the right and left shoe (Table 2).

On the basis of the measurement of the length excess of the footwear, it was found that appropriately fitted right footwear were worn by $49 \%$ of the girls while the left one by $47 \%$ of the girls. Too short right footwear had $37 \%$ of the girls and the left $-38 \%$ of the girls, while too long shoes were worn respectively by: $14 \%$ of the girls and $15 \%$ of the girls.

On the basis of measurements of the width excess of the footwear, we found that $32 \%$ of the group had appropriate footwear fitting for the right foot, and the left one $-27 \%$ of the group. Too wide footwear in relation to the right foot width had $45 \%$ of the group and in relation to the left foot: $41 \%$ of the group. Too narrow right shoes had $23 \%$ of the group and the left $-32 \%$ of the group (Table 3 ).

Table 3. Passivity of footwear in the study subjects

\begin{tabular}{|c|l|c|c|}
\hline \multirow{2}{*}{ Footwear fitting } & \multicolumn{1}{|c|}{$\begin{array}{c}\text { Right shoe } \\
(n=100)\end{array}$} & $\begin{array}{c}\text { Left shoe } \\
(n=100)\end{array}$ \\
\cline { 3 - 4 } & \multicolumn{2}{|c|}{$\%$} \\
\hline \multirow{4}{*}{ Length } & Too short & 37.0 & 38.0 \\
\cline { 2 - 4 } & Appropriate & 49.0 & 47.0 \\
\cline { 2 - 4 } & Too long & 14.0 & 15.0 \\
\hline \multirow{4}{*}{ Width } & Too narrow & 23.0 & 32.0 \\
\cline { 2 - 4 } & Appropriate & 32.0 & 27.0 \\
\cline { 2 - 4 } & Too wide & 45.0 & 41.0 \\
\hline
\end{tabular}

Table 4. Multiple regression models and simple regression, in which independent variables are excess of footwear, while dependent variables are features of the foot structure

\begin{tabular}{|c|c|c|c|c|c|c|c|}
\hline \multirow{2}{*}{ Excess of footwear } & \multicolumn{4}{|c|}{ Multiple regression } & \multicolumn{3}{|c|}{ Simple regression } \\
\hline & $R$ & $R^{2}$ & $F$ & $p$ & $b$ & $r_{c}$ & $p$ \\
\hline \multicolumn{8}{|c|}{ Summary of dependent variable regression: Clarke's angle of the right foot $\left[{ }^{\circ}\right]$} \\
\hline Length & \multirow{2}{*}{0.22} & \multirow{2}{*}{0.04} & \multirow{2}{*}{2.51} & \multirow{2}{*}{0.084} & -0.15 & -0.05 & 0.649 \\
\hline Width & & & & & 0.50 & 0.25 & $0.041 *$ \\
\hline \multicolumn{8}{|c|}{ Summary of dependent variable regression: Clarke's angle of the left foot $\left[{ }^{\circ}\right]$} \\
\hline Length & \multirow{2}{*}{0.18} & \multirow{2}{*}{0.03} & \multirow{2}{*}{1.57} & \multirow{2}{*}{0.212} & -0.10 & -0.03 & 0.739 \\
\hline Width & & & & & 0.32 & 0.17 & 0.092 \\
\hline \multicolumn{8}{|c|}{ Summary of dependent variable regression: Wejsflog index of the right foot } \\
\hline Length & \multirow{2}{*}{0.16} & \multirow{2}{*}{0.02} & \multirow{2}{*}{1.28} & \multirow{2}{*}{0.283} & 0.00 & -0.07 & 0.488 \\
\hline Width & & & & & 0.00 & -0.08 & 0.426 \\
\hline \multicolumn{8}{|c|}{ Summary of dependent variable regression: Wejsflog index of the left foot } \\
\hline Length & \multirow{2}{*}{0.23} & \multirow{2}{*}{0.05} & \multirow{2}{*}{2.78} & \multirow{2}{*}{0.066} & -0.01 & -0.18 & 0.059 \\
\hline Width & & & & & 0.01 & 0.21 & $0.036^{*}$ \\
\hline \multicolumn{8}{|c|}{ Summary of dependent variable regression: heel angle $(\gamma)$ of the right foot $\left[{ }^{\circ}\right]$} \\
\hline Length & \multirow{2}{*}{0.16} & \multirow{2}{*}{0.02} & \multirow{2}{*}{1.29} & \multirow{2}{*}{0.278} & -0.05 & -0.08 & 0.422 \\
\hline Width & & & & & 0.08 & 0.16 & 0.111 \\
\hline \multicolumn{8}{|c|}{ Summary of dependent variable regression: heel angle $(\gamma)$ of the left foot $\left[{ }^{\circ}\right]$} \\
\hline Length & 017 & 003 & 140 & 0250 & 0.07 & 0.14 & 0.156 \\
\hline Width & 0.17 & 0.03 & 1.40 & 0.250 & -0.04 & -0.14 & 0.154 \\
\hline Summar & dent $\mathrm{v}$ & le regr & : hallu & lgus ang & $\alpha)$ of the & foot $\left[^{\circ}\right.$ & \\
\hline Length & 018 & 003 & 168 & 0101 & -0.18 & -0.12 & 0.219 \\
\hline Width & 0.18 & 0.03 & 1.08 & 0.191 & -0.04 & -0.04 & 0.671 \\
\hline Summa & ndent & le regi & $\mathrm{n}$ : hall & algus an & $\alpha)$ of th & foot $\left[{ }^{\circ}\right]$ & \\
\hline Length & 015 & 003 & 126 & 0287 & -0.14 & -0.11 & 0.252 \\
\hline Width & 0.15 & 0.03 & 1.20 & 0.281 & -0.03 & -0.04 & 0.659 \\
\hline Summary of dependen & regres & the ans & the $v$ & deformity & the fifth & $\beta$ ) of th & t foot $\left[^{\circ}\right.$ \\
\hline Length & 028 & 008 & 102 & ( & -0.04 & -0.02 & 0.830 \\
\hline Width & 0.28 & 0.08 & 4.03 & $0.0 \angle 0^{\circ}$ & $0.32 *$ & 0.24 & $0.015^{*}$ \\
\hline Summary of dependen & regres & the an & f the $v$ & deformit & the fift & $(\beta)$ of th & foot $\left[{ }^{\circ}\right]$ \\
\hline Length & 005 & 000 & 014 & 0 & -0.01 & -0.01 & 0.924 \\
\hline Width & 0.05 & 0.00 & 0.14 & $0.8 / 2$ & -0.04 & -0.04 & 0.681 \\
\hline
\end{tabular}

Abbreviations: $R$ - coefficient of multiple correlation; $R^{2}$ - coefficient of determination; $F$ - the Fisher-Snedecor test; $b$ - the slope of the regression line; $r_{c}$ - partial correlation; $p$ - probability value; ${ }^{*} p<0.05$. 
Data collected in Table 4 show that multiple regression models with two explanatory variables (length and width excess of footwear) of Clarke's angle variance were statistically insignificant, both in relation to the right $(F=2.51 ; p=0.084)$ and left lower $\operatorname{limb}(F=1.57 ; p=0.212)$. The analysis of simple regression results, taking the separate influence of each of the predictors on the dependent variable into account, showed a statistically significant, positive effect of the excess of the external footwear width on Clarke's angle of the right foot $(r=0.25 ; p=0.041)$. The slope angle of the regression line for these variables was $b=0.50$, which means that if the width excess increases by a unit, then Clarke's angle will increase by an average of $0.50^{\circ}$.

Models of multiple regression defining the influence of variables: length and width excess of footwear on Wejsflog index were statistically insignificant for the right $(F=1.28 ; p=0.283)$ and left foot $(F=2.78$; $p=0.066$ ). The analysis of simple regression results, taking the exclusive influence of each of the predictors on the dependent variable into account, showed that only in the case of the left shoe, the size of the width excess has a statistically significant impact on Wejsflog index $(r=0.21 ; p=0.036)$. The slope coefficient of the regression line for these variables has reached the value of $b=0.01$. This means that the increase in the width excess by a unit affects the increase in Wejsflog index by a value of 0.01 .

The total effect of explanatory variables on the heel angle $(\gamma)$ was statistically insignificant for both the right $(F=1.29 ; p=0.278)$ and left foot $(F=1.40$; $p=0.250)$. Also, the analysis of simple regression results did not show statistically significant influence of these predictors on the dependent variable.

Models of multiple regression with two explanatory variables of hallux valgus angle $(\alpha)$ variation were statistically insignificant. Also, the analysis of simple regression results did not show statistically significant influence of the predictors on the dependent variable.

The multiple regression model with two variables explaining the angle of the varus deformity of the fifth toe $(\beta)$ was statistically significant only in the case of the right lower limb $(F=4.03 ; p=0.020)$. These variables accounted for a total of $8 \%$ of the variance of the dependent variable $\left(R^{2}=0.08\right)$. Simple regression only in the case of the right lower limb showed a statistically significant positive effect of the width excess of the footwear on the fifth toe setting $(r=0.24 ; p=$ 0.015). The slope of the regression line for these variables was $b=-0.32$, which means that if the shoe width increases by a unit, the angle of varus angle of the fifth toe will increase by an average of $0.32^{\circ}$ (Table 4).

\section{Discussion}

Issues concerning the impact of footwear on the condition of the motor system are the subject of research by many scientists. Most are focused on the frequency of deformation and the type of factors that may disturb delicate foot structure, but a small number of studies concerned on the impact of footwear on the formation of children's feet in the early school period. Abolarin et al. [1] assessed the prevalence of flat feet in 560 school-aged children living in urban and rural areas in south-western Nigeria. The results of this study show foot wear type and age as factors influencing the prevalence of flatfoot among urban and rural dwelling children, though the type of footwear was not a predictive factor. All the children in the urban area were shod with closed toe shoes while most of the children in the rural area $(69.5 \%)$ were shod with other forms of footwear. The authors noted a significantly higher percentage of feet with decreased arch in the subjects who had worn shoes in their early childhood compared to peers who did not wear shoes. Ibikunle and Ec [9] on the basis of a study of 352 Nigerian children aged $8-12$ years stated that pes planus percentage was found to be highest in children who started life by wearing cover shoes, followed by those who wore canvas, with the least percentage of pes planus found in those that wore sandals. Those who wore cover shoe more frequently had the highest percentage of pes planus occurrence, followed by those who wore sandals more frequently, then those who wore canvas more frequently with the least occurrence found in those who wore slippers. Data obtained by the authors indicate that 262 children wore indoor shoes for school. The studies did not show a significant relationship between the age in which a child began to wear shoes and flat feet. Mauch et al. [13] carried out research aimed at controlling the construction of the foot in children living on two continents: Australia and Europe. There were discrepancies in the shape of the feet, especially the longitudinal arch in children representing both populations. European children, compared to the Australian, were characterized by longer and more flat feet. The authors found that the construction of the feet depends not only on genetic factors, but also on the living environment, which determines the type of footwear worn. Therefore, the production of shoes 
should take into account the needs of customers resulting from the specificity of the place of permanent residence. In addition, the footwear assortment should meet the needs of both children with slender and wide feet providing adequate protection and comfort. Also Vergara-Amador et al. [22] compared the incidence of longitudinal flat foot depending on the type of footwear worn and the time of its use in 2 groups of children living in cities with different culture, climate and resulting footwear preferences. The first group were the inhabitants of the city of Bogotá, the capital of Colombia, where children usually wear boots for a long time during the day. In turn, the second group included children living in the city of Barranquilla in northern Colombia, at the mouth of the Magdalena River to the Caribbean Sea, where open footwear is used more often, such as sandals, and the use of shoes during the day is much less frequent. The authors found a much larger percentage of longitudinal flat foot in children from urban areas of Bogota.

Especially important issue is shoe fitting to the individual features of the feet. The measure of the degree of footwear fitting to the foot is a functional excess, which, on one hand, is a reserve for growing feet, and on the other - secures the free space in the footwear needed to lengthen the longitudinal arch (the so-called apparent increase in the length of the foot) during movement or load. The functional excess should take into account the size of the mean foot growth in the period from 6 to 12 months. In children in the early school period, the rate is on average $1 \mathrm{~cm}$ per year [23], which is why it is assumed that the functional excess, which is the difference between the foot length and the inner length of footwear for children under 15 years, should be $10 \mathrm{~mm}$ [12], [19]. Considering that the acceptable measurement error is within $\pm 2 \mathrm{~mm}$, in the interpretation of our test results, correct values of the functional length excess within 8 to $12 \mathrm{~mm}$ have been assumed. It was found that adequately fitted footwear had less than half of the girls, while too short shoes had $40 \%$ of the subjects. The rest of the girls wore too long shoes.

From the practical point of view, the width of the front part of the shoe should provide the toes with a free arrangement, in the interpretation of the results of our tests, the functional width excess was assumed in the range of 1 to $3 \mathrm{~mm}$ [12]. Approximately $30 \%$ of the studied girls wore appropriately fitted footwear, about $45 \%$ of them had too wide shoes (in the case of the right foot the percentage was higher), while too narrow shoes had $23-32 \%$ of the group. Obtained data indicate that in terms of width, footwear were poorly adjusted to the feet of the surveyed girls. This suggests the need to raise parents' awareness of the rules for the selection of footwear, as well as the need to constantly monitor its condition so that in the event of disorders, immediate replacement is made. Since this issue is occasionally undertaken in the literature of the subject, these results are difficult to refer to other reports.

An interesting issue is the impact of the size of the functional excess of footwear on the characteristics of the feet. In the case of tested footwear, the results of simple regression models in which the predictive variable constituted the width of the footwear were statistically significant. The influence of the width of the footwear on the Clarke's angle of the right foot was noted. When the width excess was larger by one unit, the Clarke's angle of the right foot increased by an average of $0.50^{\circ}$. The width of the footwear also affected the Wejsflog index of the left foot. Increasing the width excess by one unit influenced the increase of the Wejsflog index by a value equal to 0.01 , which means improved transverse arch. Therefore, it can be concluded that the functional width excess for the right foot has an influence on the shape of the longitudinal medial arch, and in the left foot - on the transverse arch. The different influence of the size of the width excess of the right and left foot may be related to the functional asymmetry of the lower limbs towards the dominance of the right lower limb as a pedipulative function and the left as a support function. It seems that in the right foot, dynamic muscle work exerts a positive effect on the shape of the foot, moreover, the dynamic function of the foot is a factor increasing the mobility of its joints. Greater mobility of the bone structure of the foot is a consequence of the loosening of joints and periarticular structures and requires greater involvement of muscles which functional efficiency determines the condition of passive stabilizers and the correct shape of the medial arch. On the other hand, in the case of the left foot, which has a static function, the pressure forces, by activating the compensation mechanisms, favorably affect the formation of the arch. In our material, a statistically significant, positive influence of the width excess of the footwear on the fifth toe setting was also noted. The slope coefficient of the regression line for these variables showed that if the shoe width increases by a unit, the angle of the fifth toe will increase by an average of $0.32^{\circ}$. And so the wider the footwear, the more deformed the fifth toe setting. A comprehensive look at the data discussed above suggests that properly chosen footwear in terms of width favors the formation of normal foot architecture, but wearing too 
wide shoes may cause excessive arches of the feet, as well as lead to instability resulting in adverse changes in the fifth toe setting.

Concluding, it should be noted that since inadequately selected footwear deforms the child's foot and affects their locomotor system and posture, the parents' knowledge and sensitivity to this aspect is essential. The conscious parent should make every effort to find the right footwear for the child, carefully observing the condition of the feet. In previous studies [18], only $40 \%$ of mothers of children in the early school period showed that they did not know about the proper selection of footwear. Lack of knowledge or insufficient awareness of the dangers resulting from negligence may be the reason for the parents' disregard for the problem. Klein et al. [11] underlined that it is necessary, from the point of view of public health, to provide parents and the general public with comprehensive information on the importance of properlyfitting shoes and the criteria of a proper fit.

To the best of our knowledge, the present study is the first multi-faceted assessment of the effect of wearing shoes. Highly homogeneous character of the study population, i.e., girls representative of an appreciable proportion of population 9-year-old girls in the Sanok administrative district and specific type of footwear regularly worn to school (outdoor footwear), stands for overall credibility of the findings. The fact of establishing with indubitable precision the key causative factors of sustaining by girls, health-hazardous deformities to their feet, also instrumental in developing potential locomotion problems in later life, offers a number of specific, health policy-oriented pointers. Further in-depth research into this issue is still required, taking into account other age and sex groups.

\section{Conclusions}

Most 9-year-old girls wear poorly fitted outdoor shoes. This points out to the need to raise parents' awareness of the principles of selection of footwear and the need to constantly monitor its condition so that in the event of irregularities, immediate replacement is made.

Increasing the functional width excess of the footwear in the case of the right foot increases the longitudinal arch and the angle of the varus deformity of the fifth toe, and in the left one - the increase in the transverse arch. Appropriately selected footwear in terms of the width favors the formation of normal foot architecture, but wearing too wide shoes in- creases the risk of hollow feet and the varus deformity of the fifth toe.

\section{References}

[1] Abolarin T., Aiyegbusi A., Tella A., Akinbo S., Predictive factors for flatfoot: The role of age and footwear in children in urban and rural communities in South West Nigeria, Foot., 2011, 21 (4), 188-192, DOI: 10.1016/j.foot.2011.07.002.

[2] Banwell H.A., Maisie E., Mackintosh P.S., Williams S.M., Paediatric flexible flat foot: how are we measuring it and are we getting it right? A systematic review, J. Foot Ankle Res., 2018, 11, 21, DOI: 10.1186/s13047-018-0264-3.

[3] D'août K., Pataky T.C., De ClercQ D., Aerts P., The effects of habitual footwear use: foot shape and function in native barefoot walkers, Footwear Sci., 2009, 1 (2), 81-94, DOI: org/10.1080/19424280903386411.

[4] Delgado-Abellán L., Aguado X., JiméneZ-Ormeño E., Mecerreyes L., Alegre L.M., Foot morphology in Spanish school children according to sex and age, Ergonomics, 2014, 57 (5), 787-797, DOI: 10.1080/00140139.2014.895055.

[5] Dinato R.C., Ribeiro A.P., Butugan M.K., Pereira I.L., ONODERA A.N., SACCO I.C., Biomechanical variables and perception of comfort in running shoes with different cushioning technologies, J. Sci. Med. Sport., 2015, 18 (1), 93-97, DOI: 10.1016/j.jsams.2013.12.003.

[6] ECHARRI J.J., FORRIOL F., The development in foot print morphology in 1851 Congolese children from Urban and rural areas, and the relationship between this and wearing shoes, J. Pediatr. Orthop., 2003, 12 (2), 141-146.

[7] Gonzalez-Martin C., Pita-Fernandez S., Seoane-Pillado T., Lopez-Calviño B., Pertega-Diaz S., Gil-Guillen V., Variability between Clarke's angle and Chippaux-Smirak index for the diagnosis of flat feet, Colomb. Med., 2017, 48 (1), 25-31.

[8] Hazzaa H.H., El-Meniawy G.H., Ahmed S.E., Bedier M.B., Correlation between gender and age and flat foot in obese children, Trends Appl. Sci. Res., 2015, 10 (4), 207-215.

[9] Ibikunle P.O., IKeKWem E.C., Prevalence of pes planus and its associated factors among primary school pupils aged 8-12 years in southeast Nigeria, Nig. J. Med. Reh., 2017, 19 (1), 1-19.

[10] Kaspiris A., Grivas T.B., Vasiliadis E., Physiological alignment of the lower limbs changes during childhood: a clinical study in south-west Greece, Adv. Biomed. Res., 2010, 1, 249-251.

[11] Klein C., Groll-Knapp E., Kundi M., Kinz W., Increased hallux angle in children and its association with insufficient length of footwear: a community based cross-sectional study, BMC Musculoskelet. Disord., 2009, 10, 159, DOI: 10.1186/ 1471-2474-10-159.

[12] KNAPIK H., The problem of the fitting of footwear used and purchased for children and youth in Poland, [in:] M. Pawłowa (Ed.), Design, materials, leather, clothing and footwear technology, Radom University of Technology, 2000, 156-165.

[13] Mauch M., Mickle K.J., Munro B.J., Dowling A.M., Grau S., Steele J.R., Do the feet of German and Australian children differ in structure? Implications for children's shoe design, Ergonomics, 2008, 51 (4), 527-539, DOI: 10.1080/ 00140130701660520 . 
[14] Mckeon P.O., Hertel J., Bramble D., Davis I., The foot core system: a new paradigm for understanding intrinsic foot muscle function, Br. J. Sports Med., 2015, 49 (5), 290, DOI: 10.1136/bjsports-2013-092690.

[15] MeI Q., Gu Y., Fernandez J., A biomechanical assessment of running with hallux unstable shoes of different material stiffness, Acta Bioeng. Biomech., 2019, 21 (1), 121-128, DOI: 10.5277/ABB-01309-2019-02.

[16] Morrison S.C., Price C., McClymont J., Nester C., Big issues for small feet: developmental, biomechanical and clinical narratives on children's footwear, J. Foot Ankle Res., 2018, 11, 39, DOI: 10.1186/s13047-018-0281-2.

[17] Puszczalowska-Lizis E., Bujas P., OMORCZyK J., Jandzis S., ZAK M., Feet deformities are correlated with impaired balance and postural stability in seniors over 75, PLoS One, 2017, 12 (9), e0183227, DOI: 10.1371/journal.pone.0183227.

[18] PuszczalowsKa-Lizis E., Jandziś S., ĆwiK K., Awareness of mothers of primary school children about the prevention of body posture defects, Med. Og. Nauk. Zdrow., 2017, 23 (2), 89-94.

[19] RAJCHEL-ChYla B., SKRZYŃSKa B., JANOCHA M., GAJEWSKI R., The foot length changes due to age as well as load during ambulation and determination of the toe allowance, Prz. Wlok., 2012, 3, 23-26.
[20] Sacco I.C.N., Onodera A.N., Bosch K., Rosenbaum D., Comparisons of foot anthropometry and plantar arch indices between German and Brazilian children, BMC Pediatr., 2015, 15, 1-6, DOI: 10.1186/s12887-015-0321-z.

[21] Wright W.G., Ivanenko Y.P., Gurfinkel V.S., Foot anatomy specialization for postural sensation and control, J. Neurophysiol., 2012, 107 (5), 1513-1521, DOI: 10.1152/ jn.00256.2011.

[22] Vergara-Amador E., SÁnchez R.F.S., Posada J.R.C., Molano A.C., Guevara O.A., Prevalence of flatfoot in school between 3 and 10 years. Study of two different populations geographically and socially, Colomb. Med., 2012, 43 (2), 141-146.

[23] VRdoljaK O., TiljaK M.K., Anthropometric measurements of foot length and shape in children 2 to 7 years of age, Period. Biol., 2017, 119 (2), 125-129, DOI: 10.18054/ pb.v119i2.4508.

[24] Xu M., Hong Y., Li J.X., Wang L., Foot morphology in Chinese school children varies by sex and age, Med. Sci. Monit., 2018, 1, 24, 4536-4546, DOI: 10.12659/ MSM.906030.

[25] Yurt Y., Sener G., Yakut Y., Footwear suitability in Turkish preschool-aged children, Prosthet. Orthot. Int., 2014, 38 (3), 224-231, DOI: 10.1177/0309364613497047. 